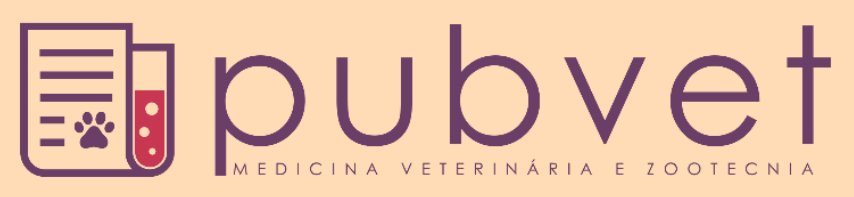

https://doi.org/10.31533/pubvet.v15n04a796.1-11

\title{
Inovações tecnológicas empregadas em coprodutos gerados pelo processamento do pescado
}

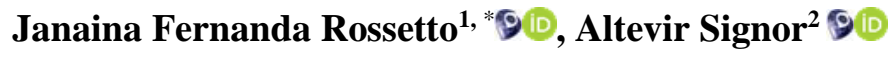 \\ ${ }^{I}$ Graduada em Engenharia de Pesca, UNIOESTE Campus Toledo-PR, Brasil. \\ ${ }^{2}$ Professor Dr., do Programa de Pós-Graduação em Recursos Pesqueiros e Engenharia de Pesca da UNIOESTE, Toledo - PR, Brasil. \\ *Autor para correspondência, E-mail: janafer_rossetto@hotmail.com
}

\begin{abstract}
Resumo. A piscicultura é uma das atividades aquícolas que mais avança na produção de alimentos e também é uma das mais questionadas em relação à sustentabilidade, visto que durante o beneficiamento do pescado, são geradas quantidades significativas de resíduos como: cabeça, vísceras, nadadeiras, cauda, coluna vertebral, escamas e restos de carne, que muitas vezes são descartadas de forma inadequada na natureza. Estes resíduos por sua vez apresentam altos níveis de proteínas e lipídeos, podendo ser processados e reaproveitados para a produção de farinha e óleo de peixe, obtenção da carne mecanicamente separada, colágeno e a gelatina, biocombustíveis como: biodiesel, biogás, e a produção de hidrolisados proteicos e concentrado proteico de pescado. Desta forma, o objetivo do presente estudo foi realizar uma revisão bibliográfica sobre as principais inovações tecnológicas empregadas no aproveitamento dos subprodutos de pescado, como forma de agregar valor a essa matéria prima, utilizada para diversos fins e refletir sobre ações que melhoram o aproveitamento e desenvolvimento de produtos biologicamente ativos.
\end{abstract}

Palavras-chave: aquicultura, processamento do pescado, subprodutos

\section{Technological innovations used in coproducts generated by fish processing}

\begin{abstract}
Fish farming is one of the aquaculture activities that most advances in food production and is also one of the most questioned in relation to sustainability, since during the processing of fish, significant amounts of waste are generated, such as head, viscera, fins, tail, spine, scales and remains of meat, which are often discarded inappropriately in nature. These residues in turn have high levels of proteins and lipids, which can be processed and reused for the production of fish flour and oil, obtaining mechanically separated meat, collagen, and gelatin, biofuels such as biodiesel, biogas, and the production of protein hydrolysates and fish protein concentrate. Thus, the objective of the present study was to carry out a bibliographic review on the main technological innovations employed in the use of fish by-products, as a way to add value to this raw material, used for various purposes and to reflect on actions that improve the use and development of biologically active products.
\end{abstract}

Keywords: aquaculture, fish processing, by-products

\section{Innovaciones tecnológicas utilizadas em coproductos generados por el procesamiento de pescado}

Resumen. La piscicultura es una de las actividades acuícolas que más avanza en la producción de alimentos y también es una de las más cuestionadas en relación a la 
sostenibilidad, ya que durante el procesamiento del pescado se generan importantes cantidades de desechos, como: cabeza, vísceras, aletas, cola, espina, escamas y restos de carne, que a menudo se desechan de forma inapropiada en la naturaleza. Estos residuos a su vez poseen altos niveles de proteínas y lípidos, los cuales pueden ser procesados y reutilizados para la producción de harina y aceite de pescado, obteniendo carne separada mecánicamente, colágeno y gelatina, biocombustibles como biodiesel, biogás y la producción de hidrolizados de proteínas y concentrado de proteínas de pescado. Así, el objetivo del presente estudio fue realizar una revisión bibliográfica sobre las principales innovaciones tecnológicas empleadas en el uso de subproductos pesqueros, como una forma de agregar valor a esta materia prima, utilizada para diversos fines y reflexionar sobre acciones que mejoren el uso y desarrollo. de productos biológicamente activos.

Palabras clave: acuicultura, procesamiento de pescado, subproductos

\section{Introdução}

Ao longo dos anos, uma das principais preocupações da sociedade moderna, é à sustentabilidade ambiental (Pires et al., 2014). Além disso, com o crescimento populacional e os impactos causados pela ação antrópica modificando continuamente o meio ambiente (Silva, 2018), um dos principais desafios dos setores agrícolas é uma produção sustentável de alimentos, visando a segurança alimentar e reduzindo os impactos ambientais gerados pela atividade (FAO, 2018).

Neste contexto, a piscicultura que está entre as atividades agrícolas que mais tem potencial para a produção de alimentos e que nos últimos anos vem se destacando das demais atividades (FAO, 2018), têm sido muito questionada em relação à sustentabilidade (Roth, 2019), isto porque durante o beneficiamento do pescado são geradas quantidades significativas de resíduos (cabeça, vísceras, nadadeiras, cauda, coluna vertebral, escamas, pele e restos de carne) (Rufino et al., 2019), que representam cerca de 65\% da biomassa total dos peixes (Sousa, 2019), e são muitas vezes descartados no meio ambiente sem nenhum tipo de tratamento (Kristinsson \& Rasco, 2000; Silva et al., 2016).

Diante disso, são empregadas tecnologias que permitam o aproveitamento desses resíduos de pescado, pois apresentam altos níveis de proteína e lipídios em sua composição, para a produção de subprodutos como: farinha e óleo de peixe, o colágeno e gelatina, a carne mecanicamente separada (CMS), os biocombustíveis como biodiesel e o biogás (Ferreira \& Braga, 2019) e a produção dos hidrolisado proteico (Oliveira Filho, 2018) e concentrados proteico de pescado (Lima, 2019), designados como ingrediente complementares para rações de peixes e outros animais (Oliveira Filho, 2018).

Diante do exposto, o objetivo do presente estudo foi realizar uma revisão, listando as principais inovações tecnológicas empregadas como forma de agregar valor aos resíduos de pescado e refletir em ações que melhoram o aproveitamento e desenvolvimento de produtos biologicamente ativos.

\section{Panorama da piscicultura no Brasil}

O setor aquícola brasileiro vem nos últimos anos apresentando um constante crescimento na produção de peixes. Segundo dados da Peixe BR (2020) no ano de 2014, a piscicultura obteve uma produção de 578.800 toneladas, e para o ano de 2019 a produção obteve um crescimento aproximado de 4,9\% em relação ao ano anterior, chegando a produzir 758.006 toneladas de peixes.

A expansão neste setor está atrelada as características naturais que o país apresenta, como: vasta disponibilidade de água doce represada, clima favorável em algumas regiões do país, extensas áreas para as instalações de viveiros escavados e tanque-redes (Brandão, 2018). Além disso, podemos destacar que o país é um dos maiores produtores de grãos, importante matéria prima para a fabricação de insumos, dispõem também de tecnologias voltadas para o setor, uma ampla quantidade de espécies nativas e exóticas, entre outras características que favorece a piscicultura no país (Schulter \& Vieira Filho, 2017).

Neste contexto, entre as principais espécies de peixes utilizadas na piscicultura, a tilápia do Nilo (Oreochromis niloticus), correspondeu a 57\% do total produzido no Brasil no ano de 2019, sendo os principais produtores: o estado do Paraná com 146.212 toneladas, São Paulo com 64.900 toneladas, Santa Catarina com 38.559 toneladas, Minas Gerais com 36.350 toneladas e Pernambuco com 25.421 
toneladas (Peixe BR, 2020). Essa espécie desperta grande interesse para o setor, pois apresentam parâmetros zootécnicos favoráveis para sua produção como: habito alimentar variado, suportam baixas taxas de oxigênio, adaptam-se bem em temperaturas que variam entre 26 e $30^{\circ} \mathrm{C}$, resistem às condições de manejo e tolera altas densidades de estocagem (Sidonio et al., 2012). Além disso, é um alimento de excelente qualidade nutricional, pois apresenta níveis adequados de proteínas, vitaminas, minerais e apresenta baixos teores de carboidrato e gorduras saturadas (Ersoy \& Özeren, 2009).

Em relação às espécies nativas, o tambaqui (Colossoma macropomum), no ano de 2017, obteve uma produção de 88,513 toneladas e correspondeu a $18,5 \%$ da produção de peixe nativos, seguido das demais espécies de peixes redondos como o pacu (Piaractus mesopotamicus), patinga (Piaractus brachypomus), tambacu (Colossoma macropomum $x$ Piaractus mesopotamicus), tambatinga (Colossoma macropomum $x$ Piaractus brachypomus), pirapitinga (Piaractus brachypomus), entre outros (IBGE, 2017). Atualmente, os principais estados produtores de peixes nativos são: Rondônia com 68.800 toneladas, Mato Grosso com 46.280 toneladas, Maranhão com 38.511 toneladas, Pará com 25.005 toneladas e Amazonas com 20.596 toneladas (Peixe BR, 2020).

\section{Processamento do pescado}

Atrelado a este cenário de crescimento da piscicultura está o aumento no processamento e comercialização de peixes em diferentes formas de apresentação. Segundo Ostrensky et al. (2000), o processamento do pescado é realizado por meio de instalações como os frigoríficos que realizam a evisceração, filetagem e/ou resfriamento, e/ou congelamento do pescado. Já a comercialização do pescado pode ser realizada, por meio do peixe inteiro, eviscerado, tronco limpo, filé e posta (Silva, 2012). Além disso, também pode ser disponibilizada ao consumidor in natura para a produção de outros pratos a base de peixe como: bolinhos, croquetes, embutidos, entre outros (Glowka et al., 2018).

Porém, durante o processamento do pescado são geradas quantidades significativas de resíduos (cabeça, vísceras, nadadeiras, cauda, coluna vertebral, escamas, pele e restos de carne) (Rufino et al., 2019), que representam cerca de 65\% da biomassa total dos peixes (Sousa, 2019) e que apresentam altos níveis de proteína e lipídios em sua composição, visto que muitas vezes são descartados de forma inadequada na natureza (Kristinsson \& Rasco, 2000; Silva et al., 2016).

Desta forma, atualmente no mercado estão sendo disponibilizadas algumas tecnologias que permite o reaproveitamento desses resíduos gerados durante o processamento do pescado, para a produção de subprodutos que pode ser utilizada para diversos fins.

\section{Inovações tecnológicas empregadas no reaproveitamento de resíduos gerados pelo processamento de pescado}

\section{Farinha e óleo de peixe}

Entre as proteínas de origem animal, a farinha e o óleo de peixes são os ingredientes mais utilizados nas formulações de rações para animais como os peixes (Tesser et al., 2019), pois o primeiro apresenta alto conteúdo proteico, com aminoácidos essenciais de alto valor biológicos, principalmente para animais monogástricos e de fácil digestão (Pires et al., 2014), já o óleo de peixe apresenta-se como uma excelente fonte de ácidos graxos da serie ômega-3 como o ácido eicosapentaenoico (EPA) e o ácido docosahexaenoico (DHA) (Engelmann, 2017).

A farinha e óleo de peixe são obtidos à partir dos resíduos gerados durante o processamento do pescado (vísceras, cabeças, pele e restos de carne) e, além disso, são obtidos também pela seleção do lote de peixes que estão fora do padrão de abate (Pires et al., 2014). Segundo Engelmann (2017) durante a produção da farinha de peixes, os resíduos passam pelo processo de moagem, cocção e prensagem, resultando em um liquido, que posteriormente é centrifugado, obtendo o óleo bruto, que passa pelo processo de secagem e moagem da fração restante. Além disso, o óleo extraído passa pelos processos de degomação, onde é refinado, eliminando grande parte dos fosfolipídios presentes, a neutralização, onde são incorporadas ao óleo, soluções salinas para a formação dos sabões, e o branqueamento do óleo (Engelmann, 2017).

Segundo Rufino et al. (2019), a farinha de peixes pode ser utilizada como ingrediente suplementar nas formulações de rações principalmente para organismos aquáticos como: os peixes, camarões, entre 
outros animais com resultados finais satisfatórios. Para aves, a farinha de peixe não é muito utilizada em sua alimentação, pois é um agente causador de doenças como a Salmonella spp. e como o ingrediente é rico em nutrientes principalmente proteínas, apresenta sensibilidade às condições de armazenamento (Rufino et al., 2019).

Em relação a aplicabilidade do óleo de peixe, atualmente está sendo empregada como matéria prima para novas tecnologias de microencapsulação e nanoencapsulação destinado a alimentação humana (Pires et al., 2014), pois permite aumentar a validade do produto final, promove a eliminação do sabor, cheiro de peixe e melhora a saúde humana devido a sua excelente fonte de ácidos graxos essenciais (Engelmann, 2017).

Porém, devido a alta demanda por farinha e óleo de peixes para alimentação animal, esses produtos se tornaram escassos e de alto custo de produção (Hardy, 2008; Tacon \& Metian, 2008). Desta forma, alguns subprodutos complementares podem ser utilizados na substituição parcial ou total da farinha e óleo de peixes, como é o caso dos hidrolisados proteicos de pescado, o concentrado proteico de pescado, etc.

\section{Carne mecanicamente separada (CMS)}

A carne mecanicamente separada é uma técnica muito utilizada como forma de agregar valor aos resíduos da carne de pescado, provenientes do processamento dos peixes e gera maior viabilidade econômica, pois somente a CMS obtida do processo de filetagem do pescado, gera um rendimento de 10 a $20 \%$ de resíduos de carne obtidos por meio da técnica de separação da carne que ficou entre as partes do pescado (Kirschnik, 2007; Neiva, 2006).

Segundo Brasil (2000), a CMS é obtida a partir do processo de separação mecânica das partes comestíveis do pescado, que ficaram nos ossos, carcaças ou partes de carcaça. Após este processo, este produto passa por uma lavagem com água ou não, em seguida, passa pelo processo de drenagem, onde é removida grande parte da água residual contida no produto, ajustando desta forma sua umidade e por fim o congelamento rápido da CMS (Jerômio, 2018), que pode variar de -30 a $-20^{\circ} \mathrm{C}$, e o tempo de conservação de três a seis meses (Dallabona et al., 2013).

Desta forma, a CMS pode ser muito utilizada na elaboração de novos produtos à base de peixes como, patê, empanados, (Kirschnik, 2007; Minozzo et al., 2009), salsichas, salames, mortadelas, croquetes, nuggets, almôndegas, fishburguers, quenelle, surimi, snack (Jerômio, 2018), bolos, quibes, entre outros (Veit et al., 2012), pois além de ser uma excelente fonte de nutrientes com níveis adequados de proteínas, ácidos graxos essenciais, minerais e vitaminas A, D e do complexo B, importantes para a saúde humana (Coradini et al., 2019), também apresentam valores nutricionais muito próximos ao encontrado nos filés de peixe como: proteína varia de 11,96 a 16,30\%, ácidos graxos insaturados de 15,37 a 3,26\% e cinzas varia de 1,22 a 0,96\% (Dallabona et al., 2013).

Segundo Boscolo et al. (2009) e Veit et al. (2012), a CMS pode ser utilizada também como suplemento alimentar na merenda escolar, pois apresenta-se como uma alternativa de baixo custo e viabilidade econômica, solucionando desta forma a desnutrição de crianças de baixa renda.

\section{Concentrado proteico de peixe}

O concentrado proteico de peixe é considerado uma alternativa de aproveitamento dos resíduos gerados durante o processamento do pescado, pois consiste em um produto de alto valor proteico (Lima, 2019), baixos níveis de umidade e gordura, apresentam alta digestibilidade, baixo custo de produção e fácil estocagem (Souza et al., 2010).

É obtido por meio de métodos químicos, onde a água e os lipídios são removidos a partir da aplicação de meios alcalinos ou solventes orgânicos como o isopropanol ou etanol, que tem como finalidade desidratar e isolar as gorduras da matéria prima, mantendo as características nutricionais e sensoriais do produto, porém suas propriedades funcionais são limitadas (Terra et al., 2008). O concentrado proteico de pescado pode ser obtido por métodos biológicos, enzimáticos ou fermentativos, onde as proteínas são desintegradas pelo método de digestão, ocorrendo desta forma a separação da água e dos lipídios, por meio da centrifugação ou filtração e pelo método físico que consiste em uma serie de técnicas de 
processamento da matéria prima, desde a prensagem mecânica ou hidráulica até as técnicas mais sofisticadas que envolvem a separação das frações aquosas e lipídicas da pasta de peixe (Lima, 2019).

Além disso, são caraterizado de três formas: tipo A: apresenta-se em forma de pó, com coloração branca ou amarela, sem odor de peixe, com 60 a $90 \%$ de proteína e $0,75 \%$ de lipídios, tipo B: onde os concentrados proteicos apresentam coloração amarelada ou acinzentada, sendo um produto com sabor e odor de peixe, com um conteúdo proteico abaixo de $65 \%$ e até $10 \%$ de gordura e o tipo C: formado a partir de uma farinha não desodorizada, com até $60 \%$ de proteína e sem uma taxa máxima de lipídeos (Ordóñes et al., 2005).

Segundo Ordóñes et al. (2005), o concentrado proteico de pescado do tipo A é o mais utilizado atualmente e pode ser aplicado como ingredientes para pães, biscoitos, massas, sopas, molhos, alimentos infantis, pratos prontos, entre outros, devido ao seu alto conteúdo proteico e baixos teores de gordura. Segundo Goes et al. (2016) essa a inclusão é considerada uma forma de aumentar o consumo de peixe no país, já que é um produto com uma excelente fonte de nutrientes.

\section{Hidrolisado proteico de pescado}

O hidrolisado proteico é uma tecnologia muito empregada no aproveitamento dos resíduos gerados durante o processamento do pescado. São formados a partir da digestão das proteínas, onde por meio de processos químicos (ácido ou alcalino) ou enzimáticos, ocorre à quebra das cadeias polipeptídicas, originando aminoácidos livres e moléculas bioativas (Kristinsson \& Rasco, 2000), os quais apresentam tamanhos variados, diferenciando somente em suas características nutricionais e no sabor do alimento (Guadix et al., 2000).

Segundo Sousa (2019) o processo de hidrólise química envolve a utilização de ácidos ou bases, não é muito utilizada para a produção dos hidrolisados proteicos, sendo mais utilizado para a preparação de ensilados de pescado, por exemplo, onde são utilizadas soluções como: o ácido fórmico, bactérias láticas, fontes de hidratos de carbono, entre outros. Além disso, não é muito utilizada devido a fortes odores emitidos pela matéria prima em decomposição (Zamora-Sillero et al., 2018).

Desta forma, utiliza-se mais o processo enzimático para produção de hidrolisados proteicos, sendo as hidrolases, carboidrases, proteases e lipases, as enzimas mais utilizadas pelas indústrias de alimentos (Whitaker, 1993). Neste processo as enzimas irão atuar como catalisadores biológicos, ligando-se em sítios ativos específicos do substrato, aumentando desta forma a velocidade da reação, viabilizando a conversão dos resíduos de pescado em um alimento de alto valor nutricional (Centenaro et al., 2009) e produzindo muitas moléculas bioativas na forma de peptídeos, polipeptídios e aminoácidos livres, que apresentam importante bioatividades metabólicas nos animais (Centenaro et al., 2009).

Porém, durante este processo, alguns fatores devem ser considerados, como: $\mathrm{pH}$, temperatura, relação substrato/enzima, grau de hidrólise, entre outros que irão atuar diretamente na produção dos hidrolisados proteicos (Centenaro et al., 2009). Segundo Lunelli (2015), a variação da temperatura pode interferir na quebra das ligações peptídicas das proteínas na fração solúvel e influenciar na relação substrato/enzima. Também, o controle do pH, temperatura e tempo de reação, favorece o aumento da ação das enzimas, viabilizando o processo de hidrólise enzimática (Zavareze et al., 2009). Além disso, a inativação das enzimas pode ser realizada por métodos químicos ou térmicos, através da variação do $\mathrm{pH}$ ou pelo aumento da temperatura (Centenaro et al., 2009), e o grau de hidrólise que determina a porcentagem de ligações peptídicas digeridas ao longo da reação (Adler-Nissen, 1979), onde por meio desta equação, determina-se a eficiência do processo de hidrólise na quebra das moléculas proteicas e a provável característica funcional dos hidrolisados, como alimento nutricional (Lunelli, 2015).

Em relação a sua aplicabilidade, o hidrolisado proteico de pescado pode ser utilizado como ingrediente em rações para animais, como: peixes marinhos e de água doce, camarões, bezerros, leitões, entre outros, pois apresenta diversas propriedades funcionais que melhoram a digestibilidade do alimento principalmente na fase inicial de vida, melhora na absorção dos nutrientes (Kristinsson \& Rasco, 2000). Além disso, os hidrolisados contém peptídeos bioativos que ao serem incrementados na dieta animal, podem, consequentemente, melhorar as respostas metabólicas e fisiológicas, diminuindo o risco de doenças e mantendo a saúde do animal (Anjo, 2020; Vioque et al., 2006), também podem 
atuar como antibióticos, hormônios, antioxidantes, inibidores e reguladores de atividades enzimáticas (Ribeiro et al., 2016).

\section{Colágeno e gelatina de peixe}

O colágeno é um subproduto do pescado, considerado uma biomolécula natural rica em aminoácidos, formada por proteínas fibrosas, encontradas principalmente no tecido conjuntivo (Lopes, 2018) e unidas por três cadeias polipeptídicas helicoidais, conhecidas como cadeia $\alpha$, que apresentam rotação no sentido horário e se enovelam para formar uma tripla hélice (Roberto, 2017). Essas cadeias polipeptídicas contem $30 \%$ de glicina, $12 \%$ de prolina, $11 \%$ de alanina, $10 \%$ de hidroxiprolina, $1 \%$ de hidroxilisina e pequenas quantidades de aminoácidos polares e carregados (Lopes, 2018).

Além disso, o colágeno apresenta 29 tipos de proteínas que diferem na composição molecular e na distribuição tecidual, sendo a proteína do tipo I (Tripocolágeno) (Masayoshi \& Everardo, 1999) a mais abundante, principalmente nos peixes, localizada na pele, escamas, barbatanas, bexiga natatória, ossos, espinhas e musculo (Liu et al., 2012). Segundo Makareeva \& Leikin (2014) esta proteína desempenha um importante papel na vida dos seres humanos, pois atuam principalmente na formação de novos tecidos, ossos, órgãos, vasos sanguíneos, entre outros.

Segundo Monte (2016), outra característica importante do colágeno é que ele pode ser desnaturado em temperatura ambiente. Isso está associada a sua cadeia $\alpha$ secundária presente somente nesta proteína (Gly-X-Pro ou Gly-X-4-Hyp) e que se repete diversas vezes, sendo formada por uma estrutura helicoidal de orientação para a esquerda e com a formação de três resíduos por volta (Monte, 2016), no qual o resíduo de glicina se torna percursor para formação da tripla hélice e a prolina e hidroxiprolina são responsáveis pela formação da torção da hélice do colágeno (Lehninger, 2006). Além disso, a estabilidade da molécula de colágeno pode ser influenciada pelas ligações de Van der Waals, hidrofóbica e eletrostática (Monte, 2016).

Em relação a sua extração, o colágeno pode ser obtido pelos métodos que envolvem a ação de enzimas, sais neutros ou alcalinos e os ácidos acéticos ou propiônico, ou uma combinação de ambos os métodos (Krishnamoorthi et al., 2017; Masilamani et al., 2016; Zeugolis \& Raghunath, 2011). Segundo Sousa (2008), a utilização de ácidos para a solubilização e sais para a precipitação, são os métodos mais utilizados, além disso, segundo Huang et al. (2016), também é considerado o mais rigoroso, pois envolve um longo processo de reação e requer temperaturas de até $75^{\circ} \mathrm{C}$. Já os métodos que envolvem a utilização de enzimas e meios ácidos, são caracterizados por um período de até 192 horas, além da utilização de $\mathrm{NaOH}$, ácido acético, pepsina e $\mathrm{NaCl}$ (Huang et al., 2016).

Desta forma, a extração do colágeno pode ser realizada por meio da hidrólise enzimática, onde ocorre a quebra das ligações polipeptídicas pela ação de uma enzima conhecida como colágenase (Roberto, 2017). Além disso, neste processo, é realizado o tratamento térmico, com temperaturas que variam desde $60^{\circ} \mathrm{C}$ até $90^{\circ} \mathrm{C}$ (Carvalho, 2002), para que ocorra a desestabilização da tripla hélice, ou seja, a quebra das ligações covalentes e de hidrogênio (Montero, 2000), sendo que durante o processo de extração do colágeno, o pH é monitorado constantemente para garantir a manutenção das propriedades físicas do produto final, e por fim sua conversão em gelatina (Carvalho, 2002), onde são aplicadas temperaturas moderadas, devido a suas propriedades físicas e químicas (Kołodziejska et al., 2008), resultando em uma proteína biologicamente ativa constituída por tirosina, cistina e metionina, sendo ausente de triptofano.

Desse modo, podemos dizer que o colágeno e a gelatina são produtos de excelente qualidade nutricional com aplicação em indústrias alimentícias, como produtos para o amolecimento de carnes ou como ingredientes para o preparo de alimentos e nas indústrias farmacêuticas é usado em formulações para medicamentos e cosméticos (Raskovic et al., 2014; Suphatharaprateep et al., 2011).

Segundo Kumar et al. (2011), as moléculas bioativas extraídas das escamas de peixes, podem atuar também em diversas partes do nosso corpo, auxiliando na absorção dos nutrientes no intestino delgado, no tecido conjuntivo, ossos, vasos sanguíneos e na pele. Além disso, por apresentarem biomolécula natural, atuam também na reconstrução de tecidos moles (Chen et al., 2000), comprometidos por queimaduras (Tabata et al., 2000). 


\section{Biocombustivel}

O biodiesel é considerado um biocombustível, formado a partir do processo de transesterificação, que consiste em uma serie de reações químicas, que envolve a utilização de um álcool especifico (álcool primário, metanol ou etanol) de cadeia curta, que na presença de uma base ou um ácido forte (Cunha et al., 2009), reage com os triglicerídeos presentes nos óleos vegetais, animais ou nas gorduras, produzindo éster e glicerina (Ferreira, 2017). Segundo Costa (2017), o éster só pode ser comercializado após passar pelo processo de purificação, onde serão realizadas modificações especificas em suas propriedades funcionais, garantindo assim um produto final de qualidade, destinado principalmente para a utilização em motores de ignição por compreensão.

Além dos óleos e gorduras empregados como fonte para a produção de biodiesel, atualmente estão sendo inclusos os óleos de peixe, óbitidos a partir do processamento da carcaça de pescado após seu processamento industrial (Krause, 2008; Pittigliani, 2014), pois esse produto tem como vantagem um alto valor calórico, um grande número de cetanos e uma estabilidade a oxidação (Ferreira, 2017).

Desta forma, o biodiesel produzido a partir de óleo de peixe se torna uma fonte alternativa rentável na produção de biocombustível, utilizados principalmente por veículos leves, caminhões, tratores e geradores, pois apresenta-se como uma alternativa sustentável para a diminuição de resíduos de pescado e na diminuição da emissão de gases poluentes (Ferreira, 2017).

O biogás também é considerado uma alternativa sustentável na produção de biocombustível, pois é produzido a partir de biodigestor, onde ocorre a mistura de gases como metano, gás carbônico, sulfeto de hidrogênio, vapor de água, nitrogênio, hidrogênio, entre outros, em um processo conhecido como biodigestão (Weiland, 2010).

Nesse processo, os carbonos presentes nos resíduos como vísceras de peixes, por exemplo, são hidrolisados pelas bactérias fermentativas, obtendo como produto os ácidos orgânicos e álcoois, em seguida, esses produtos são convertidos em acetato, hidrogênio e gás carbônico, pelas bactérias acetogênicas e ao final do processo ocorre a produção do $\mathrm{CH}_{4}$ e $\mathrm{CO}_{2}$ através da conversão dos ácidos orgânicos, álcoois, acetato, hidrogênio e gás carbônico pelas bactérias metanogênicas (Schmidell et al., 2001). Além disso, durante o processo de produção do biogás é importante monitorar o pH, temperatura e a relação de carbono/nitrogênio do sistema (Comastri-Filho, 1981).

Neste contexto, o biogás pode ser aplicado como fonte de energia em sistemas de aquecimentos (fornos, fogões, caldeiras, etc), para geração de eletricidade e para combustão interna de motores (Comastri-Filho, 1981).

\section{Considerações finais}

A sustentabilidade têm sido uma das principais preocupações da sociedade atual e atrelado a isso, as indústrias processadoras de pescado, que atualmente geram quantidades significativas de resíduos, buscam meios tecnológicos sustentáveis que permite o aproveitamento desses resíduos, agregando valor a esta matéria prima por meio da geração de subprodutos de pescado de alto valor nutricional, utilizados para diversos fins.

Essas tecnologias minimizam os impactos gerados pelo descarte dos resíduos ao meio ambiente e os subprodutos elaborados a partir desses resíduos tornam-se fonte de renda extra para muitas empresas e indústrias que podem elevar sua renda, através da elaboração de novos produtos utilizados para alimentação humana assim como para animais.

\section{Referências}

Adler-Nissen, J. (1979). Determination of the degree of hydrolysis of food protein hydrolysates by trinitrobenzenesulfonic acid. Journal of Agricultural and Food Chemistry, 27(6), 1256-1262.

Anjo, D. F. C. (2020). Alimentos funcionais em angiologia e cirurgia vascular. Jornal Vascular Brasileiro, 3(2), 145-154.

Boscolo, W. R., Feiden, A., Maluf, M. L. F., \& Veit, J. C. (2009). Peixe na merenda escolar: educar e formar novos consumidores. Toledo: GFM Gráfica e Editora. 
Brandão, C. S. (2018). Perrspectivas do desenvolvimento da piscicultura no Brasil: um enfoque na produção de tilápias nos últimos dez anos. Monografia em Ciências Econômicas, Universidade Federal da Bahia.

Brasil. (2000). Instrução Normativa ${ }^{\circ} 4$ de 31 de março de 2000 da Secretaria de Defesa Agropecuária do Ministério da Agricultura e do Abastecimento. Aprova os Regulamentos Técnicos de Identidade e Qualidade de Carne Mecanicamente Separada, de mortadela, de linguiça e de . Diário Oficial Da Republica Federativa Do Brasil, Poder Executivo, 1-10.

Carvalho, R. A. (2002). Elaboração e caracterização de filmes à base de gelatina modificada enzimática e quimicamente [Tese (doutorado) - Universidade Estadual de Campinas, Faculdade de Engenharia de Alimentos, Campinas, SP]. http://www.repositorio.unicamp.br/handle/REPOSIP/255961

Centenaro, G. S., Prentice-Hernández, C., Salas-Mellado, M., \& Netto, F. M. (2009). Efeito da concentração de enzima e de substrato no grau de hidrólise e nas propriedades funcionais de hidrolisados proteicos de corvina (Micropogonias furnieri). Química Nova, 32(7), 1792-1798. https://doi.org/10.1590/S0100-40422009000700021

Chen, Y.-S., Hsieh, C.-L., Tsai, C.-C., Chen, T.-H., Cheng, W.-C., Hu, C.-L., \& Yao, C.-H. (2000). Peripheral nerve regeneration using silicone rubber chambers filled with collagen, laminin and fibronectin. Biomaterials, 21(15), 1541-1547. https://doi.org/10.1016/S0142-9612(00)00028-4

Comastri-Filho, J. A. (1981). Independência energética do pantanal matogrossense. EMBRAPA, Corumbá-MS, Circular Técnica, 9.

Coradini, M. F., Maia, K., Pinaffi, D. L., Testi, I., Nunes, M. L., \& Souza, M. L. R. (2019). Blocos salgados desidratados de CMS de tilápia do Nilo com adição de casca de ovos e diferentes espécies de peixes marinhos. Encontro Internacional de Produção Cientifica, 11.

Costa, G. R. R. (2017). Óleo extraído das vísceras da tilápia do Nilo: pré-tratamento, adequação e produção de biodiesel. Monografia (Graduação em Engenharia de Petróleo) - Universidade Federal do Ceará, Fortaleza.

Cunha, M. E., Krause' C. L., Moraes, M. S. A., Faccini, CS., Jacques' R. A., Almeida' S. R., Rodrigues, M. R. A \& Caramão, E. B. (2009). Beef tallow biodiesel produced in a pilot scale. Fuel Processing Technology, 90(4), 570-575

Dallabona, B. R., Karam, L. B., Wagner, R., Bartolomeu, D. A. F. S., Mikos, J. D., Francisco, J. G. P., Macedo, R. E. F., \& Kirschnik, P. G. (2013). Effect of heat treatment and packaging systems on the stability of fish sausage. Revista Brasileira de Zootecnia, 42(12), 835-843. https://doi.org/10.1590/S1516-35982013001200001

Engelmann, J. I. (2017). Obtenção de lipídios estruturados a partir de gordura animal e óleo de pescado. Dissertação de Mestrado em Engenharia e Ciências de Alimentos, Pós-Graduação em Engenharia de Alimentos, Universidade Federal do Rio Grande.

Ersoy, B., \& Özeren, A. (2009). The effect of cooking methods on mineral and vitamin contents of African catfish. Food Chemistry, 115(2), 419-422. https://doi.org/10.1016/j.foodchem.2008.12.018

FAO. (2018). The state of world fisheries and aquaculture. Hermetia Ilucens, 227.

Ferreira, A. G. (2017). Prospecção tecnológica sobre as técnicas de obtenção de óleo de resíduos de peixe. Trabalho de Conclusão de Curso (Bacharelado em Engenharia de Energia)-Universidade de Brasília, Brasília.

Ferreira, A. G., \& Braga, P. R. S. (2019). Mapeamento Tecnológico sobre as Técnicas de Obtenção de Óleo de Resíduos de Peixe. Cadernos de Prospecção, 12(5 Especial), 1516.

Glowka, R. P., Weingartner, M., \& Muelbert, B. (2018). Produção e comercialização de pescado no município de Laranjeiras do Sul, Paraná. Revista Verde de Agroecologia e Desenvolvimento Sustentável, 13(4), 531-543.

Goes, E. S. R., Souza, M. L. R., Michka, J. M. G., Kimura, K. S., Lara, J. A. F., Delbem, A. C. B., \& Gasparino, E. (2016). Fresh pasta enrichment with protein concentrate of tilapia: nutritional and sensory characteristics. Food Science and Technology, 36(1), 76-82. https://doi.org/10.1590/1678457X.0020

Guadix, A., Guadix, E. M., Páez-Dueñas, M. P., González-Tello, P., \& Camacho, F. (2000). Procesos 
tecnológicos y métodos de control en la hidrólisis de proteínas. Ars Pharmaceutica, 41(1), 79-89.

Hardy, R. W. (2008). Farmed fish diet requirements for the next decade and implications for global availability of nutrients. Alternative Protein Sources in Aquaculture Diets, 1-15.

Huang, C.-Y., Kuo, J.-M., Wu, S.-J., \& Tsai, H.-T. (2016). Isolation and characterization of fish scale collagen from tilapia (Oreochromis sp.) by a novel extrusion-hydro-extraction process. Food Chemistry, 190, 997-1006. https://doi.org/10.1016/j.foodchem.2015.06.066

IBGE. (2017). Produção da Pecuária Municipal - PPM. Instituto Brasileiro de Geografia e Estatística. https://www.ibge.gov.br/estatisticasnovoportal/economicas/agriculturaepecuaria/9107producaodapecuariamunicipal.html?\&t=resultados

Jerômio, H. M. A. (2018). Elaboração de embutido emulsionado tipo mortadela de carne mecanicamente separada de Tilápia do Nilo (Oreochromus niloticus) adicionado de teores reduzidos de gordura suína. Tese de doutorado em Ciências dos Alimentos, Pós-Graduação em Nutrição, Universidade Federal de Pernambuco.

Kirschnik, P. G. (2007). Avaliação da estabilidade de produtos obtidos de carne mecanicamente separada de tilápia nilótica (Oreochromis niloticus) [Tese (doutorado) - Universidade Estadual Paulista, Centro de Aqüicultura]. http://hdl.handle.net/11449/100195

Kołodziejska, I., Skierka, E., Sadowska, M., Kołodziejski, W., \& Niecikowska, C. (2008). Effect of extracting time and temperature on yield of gelatin from different fish offal. Food Chemistry, 107(2), 700-706. https://doi.org/10.1016/j.foodchem.2007.08.071

Krause, L. C. (2008). Desenvolvimento do processo de produção de biodiesel de origem animal (p. 147). Tese (Doutorado em Química) - Universidade Federal do Rio Grande do Sul.

Krishnamoorthi, J., Ramasamy, P., Shanmugam, V., \& Shanmugam, A. (2017). Isolation and partial characterization of collagen from outer skin of Sepia pharaonis (Ehrenberg, 1831) from Puducherry coast. Biochemistry and Biophysics Reports, 10, 39-45. https://doi.org/10.1016/j.bbrep.2017.02.006

Kristinsson, H. G., \& Rasco, B. A. (2000). Biochemical and Functional Properties of Atlantic Salmon ( Salmo salar ) Muscle Proteins Hydrolyzed with Various Alkaline Proteases. Journal of Agricultural and Food Chemistry, 48(3), 657-666. https://doi.org/10.1021/jf990447v

Kumar, M. H., Spandana, V., \& Poonam, T. (2011). Extraction and determination of collagen peptide and its clinical importance from tilapia fish scales (Oreochromis niloticus). International Research Journal of Pharmacy, 2(10), 97-99.

Lehninger, N. D. L. (2006). Principios de bioquímica. São Paulo.

Lima, G. L. (2019). Concentrado proteico de tambaqui: obtenção, estudo e aplicação no desenvolvimento de snack extrusado. Monografia (Graduação em Engenharia de Alimentos), Fundação Universidade Federal de Rondônia, Ariquemes.

Liu, D., Liang, L., Regenstein, J. M., \& Zhou, P. (2012). Extraction and characterisation of pepsin-solubilised collagen from fins, scales, skins, bones and swim bladders of bighead carp (Hypophthalmichthys nobilis). Food Chemistry, 133(4), 1441-1448. https://doi.org/10.1016/j.foodchem.2012.02.032

Lopes, N. V. (2018). Avaliação das propriedades físico-químicas do colágeno extraído do coproduto de tilápia. Universidade Tecnológica Federal do Paraná.

Lunelli, T. (2015). Reciclagem de resíduos do processamento de tilápia (Oreochromis niloticus) visando obter hidrolisado proteico como coproduto. Dissertação de Mestrado - Universidade de São Paulo.

Makareeva, E., \& Leikin, S. (2014). Collagen Structure, Folding and Function. In Osteogenesis Imperfecta (pp. 71-84). Elsevier. https://doi.org/10.1016/B978-0-12-397165-4.00007-1

Masayoshi, P., \& Everardo, D. (1999). Manual de Pesca-Ciência e Tecnologia do Pescado. São Paulo: Varela, 1, 464.

Masilamani, D., Madhan, B., Shanmugam, G., Palanivel, S., \& Narayan, B. (2016). Extraction of collagen from raw trimming wastes of tannery: a waste to wealth approach. Journal of Cleaner Production, 113, 338-344. https://doi.org/10.1016/j.jclepro.2015.11.087

Minozzo, M. G., Waszczynskyj, N., \& Boscolo, W. R. (2009). Utilização de carne mecanicamente separada de tilápia (Oreochromis niloticus) para a produção de patês cremoso e pastoso. Alimentos 
e Nutrição Araraquara, 19(3), 315-319.

Monte, F. T. D. (2016). Caracterização do colágeno extraído a partir de escamas de pescada amarela (Cynoscion acoupa). Universidade Federal de Pernambuco.

Montero, P. (2000). Extracting Conditions for Megrim Skin Collagen Affect Functinal Properties of the Restulting Gelatin. Food Chemistry and Toxicology, 65(3), 437-454.

Neiva, C. R. P. (2006). Aplicação da tecnologia de carne mecanicamente separada-CMS na indústria de pescado. Simpósio de Controle do Pescado, 2, 2006.

Oliveira Filho, J. G. (2018). Obtenção de peptídeos bioativos a partir de subprodutos de algodão para aplicação em filmes ativos e biodegradáveis. Dissertação (Mestrado em Agroquímica), Instituto Federal Goiano.

Ordóñes, J. Á., Rodriguez, M. I. C., Sanz, M. L. G., Minguillón, G., Perales, L. H., \& Cortecero, M. D. S. (2005). Tecnologia de alimentos: alimentos de origem animal. Porto Alegre: Artmed, 2, 41.

Ostrensky, A., Borghetti, J. R., \& Pedini, M. (2000). Situação atual da aqüicultura brasileira e mundial. Aquicultura No Brasil: Bases Para Um Desenvolvimento Sustentável. Brasília, DF: CNPq, 354381.

Peixe BR. (2020). Anuário Peixe Br da Piscicultura 2020. São Paulo: Associação Brasileira de Piscicultura.

Pires, D. R., Morais, A. C. N., Costa, J. F., Araújo, L. C. D. S., \& Oliveira, G. M. (2014). Aproveitamento do resíduo comestível do pescado: Aplicação e viabilidade. Revista Verde de Agroecologia e Desenvolvimento Sustentável, 9(5), 34-46.

Pittigliani, A. H. (2014). Resíduos de pescado: produção de biodiesel e extração de colágeno produção de biodiesel e extração de colágeno. Monografia de Conclusão de Curso em Medicina Veterinária, Universidade Federal do Rio Grande do Sul.

Raskovic, B., Bozovic, O., Prodanovic, R., Niketic, V., \& Polovic, N. (2014). Identification, purification and characterization of a novel collagenolytic serine protease from fig (Ficus carica var. Brown Turkey) latex. Journal of Bioscience and Bioengineering, 118(6), 622-627. https://doi.org/10.1016/j.jbiosc.2014.05.020

Ribeiro, M. S., Affonso, E. G., Santos, D. L., Storti Filho, A., Pereira, M. I. O., \& Gonçalves, L. U. (2016). Hidrolisado proteico de peixe em dietas para juvenis de pirarucu. Anais do Aquaciência.

Roberto, N. A. (2017). Produção de peptídeos bioativos a partir do colágeno isolado de dourado (Coryphaena hippurus). Universidade Federal de Pernambuco.

Roth, K. C. (2019). Panorama da inovação na tilapicultura: uma análise da base de dados de patentes do setor [Dissertação de Mestrado em Economia e Gestão do Agronegócio, Programa de PósGraduação em Agronegócio, Fundação Getúlio Vargas - Escola de Economia de São Paulo]. https://hdl.handle.net/10438/27352

Rufino, J. P. F., Cruz, F. G. G., Guimarães, C. C., Silva, A. F., \& Batalha, O. S. (2019). Uso de subprodutos do pescado na alimentação de aves. Revista Científica de Avicultura e Suinocultura, $5(1)$.

Schmidell, W., de Almeida Lima, U., Borzani, W., \& Aquarone, E. (2001). Biotecnologia industrialvol. 2: engenharia bioquímica (Vol. 2). Editora Blucher.

Schulter, E. P., \& Vieira Filho, J. E. R. (2017). Evolução da piscicultura no Brasil: Diagnóstico e desenvolvimento da cadeia produtiva de tilápia. Ipea: Texto para Discussão.

Sidonio, L., Cavalcanti, I., Capanema, L., Morch, R., Magalhães, G., Lima, J., Burns, V., Alves Júnior, A. J., \& Mungioli, R. (2012). Panorama da aquicultura no Brasil: desafios e oportunidades. BNDES Setorial, 35, 421-463.

Silva, C. D. M., Pires, C. R. F., Sousa, D. N., Chicrala, P. C. M. S., \& Santos, V. R. V. (2016). Evaluation sensory of canned matrinxã (Brycon amazonicus) in vegetable oil. Journal of Bioenergy and Food Science, 3(3), 161-169.

Silva, T. B. (2018). Tecnologia de bioflocos (BFT) no desempenho de peixes ornamentais. Trabalho de Conclusão de curso (Tecnólogo em Aquicultura) - Universidade Federal do Pampa, Campus 
Uruguaiana, Uruguaiana.

Silva, L. A. (2012). Oferta de pescado no mercado da cidade de Porto Alegre e caracterização das principais espécies.

Sousa (2008)

Sousa, V. F. (2019). Preparação e caracterização de hidrolisados proteicos de tilápia [Lisboa: ISA]. http://hdl.handle.net/10400.5/18374

Souza, J. F., Bittencout, N. N., Gomes, C. S., Oliveira, J. K., Santos, R. M., Reis, I. A. O., Nunes, M. L., \& Narain, N. (2010). Desenvolvimento e caracterização físico-química e sensorial de nuggets formulados com concentrado protéico de pescado - MARINE BEEF. Scientia Plena, 6(3), 1-4.

Suphatharaprateep, W., Cheirsilp, B., \& Jongjareonrak, A. (2011). Production and properties of two collagenases from bacteria and their application for collagen extraction. New Biotechnology, 28(6), 649-655. https://doi.org/10.1016/j.nbt.2011.04.003

Tabata, K., Fukushima, K., Oda, K., \& Okura, I. (2000). Selective aggregation of zinc phthalocyanines in the skin. Journal of Porphyrins and Phthalocyanines, 4(3), 278-284. https://doi.org/https://doi.org/10.1002/(SICI)10991409(200004/05)4:3<278::AID-JPP214>3.0.CO;2-M

Tacon, A. G. J., \& Metian, M. (2008). Global overview on the use of fish meal and fish oil in industrially compounded aquafeeds: Trends and future prospects. Aquaculture, 285(1), 146-158.

Terra, N. N., Abreu, L. E. V, Meller, A. C., \& Mussoi, E. (2008). Concentrado proteíco de peixe. Revista do Centro de Ciências Rurais, 5(3).

Tesser, M. B., Cardozo, A. P., Camaño, H. N., \& Wasielesky, W. (2019). Substituição da farinha e do óleo de peixe por farinha e óleo de origem vegetal em rações utilizadas na fase de engorda do camarão-branco-do-pacífico Litopenaeus vannamei, em sistemas de bioflocos. Arquivo Brasileiro de Medicina Veterinária e Zootecnia, 71(2), 703-710. https://doi.org/10.1590/1678-4162-10354

Veit, J. C., Freitas, M. B., Reis, E. S., Moore, O. Q., Finkler, J. K., Boscolo, W. R., \& Feiden, A. (2012). Desenvolvimento e caracterização de bolos de chocolate e de cenoura com filé de tilápia do nilo (Oreochromis niloticus). Brazilian Journal of Food \& Nutrition/Alimentos e Nutrição, 23(3).

Vioque, J., Pedroche, J., Yust, M. M., Lqari, H., Megías, C., Girón-Calle, J., Alaiz, M., \& Millán, F. (2006). Peptídeos bioativos em proteínas vegetais de reserva. Brazilian Journal of Food Technology, 16, 99-102.

Weiland, P. (2010). Biogas production: current state and perspectives. Applied Microbiology and Biotechnology, 85(4), 849-860. https://doi.org/10.1007/s00253-009-2246-7

Whitaker, J. R. (1993). Principles of Enzymology for the Food Sciences, Second Edition,. Taylor \& Francis. https://books.google.com.br/books?id=ySi_pbehlOoC

Zamora-Sillero, J., Gharsallaoui, A., \& Prentice, C. (2018). Peptides from Fish By-product Protein Hydrolysates and Its Functional Properties: an Overview. Marine Biotechnology, 20(2), 118-130. https://doi.org/10.1007/s10126-018-9799-3

Zavareze, E. R., Silva, C. M., Salas-Mellado, M., \& Prentice-Hernández, C. (2009). Funcionalidade de hidrolisados proteicos de cabrinha (Prionotus punctatus) obtidos a partir de diferentes proteases microbianas. Química Nova, 32(7), 1739-1743. https://doi.org/10.1590/S0100-40422009000700011

Zeugolis, D. I., \& Raghunath, M. (2011). Collagen: materials analysis and implant uses. Comprehensive Biomaterials, 261-278.

Histórico do artigo:

Recebido: 21 de outubro de 2020.

Aprovado: 8 de dezembro de 2020

Disponível online: 5 de março de 2021.
Licenciamento: Este artigo é publicado na modalidade Acesso Aberto sob a licença Creative Commons Atribuição 4.0 (CC-BY 4.0), a qual permite uso irrestrito, distribuição, reprodução em qualquer meio, desde que o autor e a fonte sejam devidamente creditados. 